CLINICAL STUDY

\title{
Metabolic syndrome and its components are associated with increased thyroid volume and nodule prevalence in a mild-to-moderate iodine-deficient area
}

\author{
Semra Ayturk, Alptekin Gursoy, Altug Kut, Cuneyd Anil, Asli Nar and Neslihan Bascil Tutuncu \\ Department of Endocrinology and Metabolism, Baskent University Faculty of Medicine, 5 Cadde No. 48, 06490 Bahcelievler, Ankara, Turkey \\ (Correspondence should be addressed to A Gursoy; Email: alptekingursoy@hotmail.com)
}

\begin{abstract}
Objective: Metabolic syndrome (MetS) is a cluster of metabolic abnormalities with insulin resistance (IR) as a major component. It has been recently questioned whether MetS and its related components are associated with functional and morphological alterations of the thyroid gland. The aim of our study is to examine thyroid volume and nodule prevalence in a case-control study of patients with MetS in a mild-to-moderate iodine-deficient area.

Design: Two hundred and seventy-eight patients with MetS were randomly matched for age, gender, and smoking habits with 261 subjects without MetS. Serum TSH, free tri-iodothyronine and thyroxine, and the level of IR, which was estimated by the homeostasis model assessment for IR, as well as other MetS parameters were evaluated. Thyroid ultrasonography was performed in all subjects. All subjects with thyroid nodules $>1 \mathrm{~cm}$ were offered to undergo thyroid fine needle aspiration biopsy.

Results: TSH was significantly positively correlated with the presence of MetS diagnosis. There was no association between free thyroid hormone levels and MetS and its related components. Mean thyroid volume was significantly higher in patients with MetS than in controls $(17.5 \pm 5.5 \mathrm{vs} 12.2 \pm 4.2 \mathrm{ml}$, $P<0.0001)$. Also the percentage of patients with thyroid nodules was significantly higher in patients with MetS (50.4 vs $14.6 \%, P<0.0001$ ). Subjects were also divided into two groups according to the presence of IR. The group of subjects with IR had increased thyroid volume and nodule formation. The odds ratio for the development of thyroid nodule in the presence of IR was 3.2. TSH as well as all MetS components were found to be independent predictors for thyroid volume increase. IR but not TSH was found to be correlated with thyroid nodule formation. Thyroid cancer was diagnosed in 3 out of 38 patients with MetS who agreed to have a biopsy (7.9\%). None of the subjects in the control group was diagnosed to have thyroid cancer.

Conclusions: The results suggest that patients with MetS have significantly increased thyroid volume and nodule prevalence. Multivariate regression analysis model demonstrated that the presence of IR contributed substantially to this increased risk. Our data provide the first evidence that IR is an independent risk factor for nodule formation in an iodine-deficient environment.
\end{abstract}

European Journal of Endocrinology 161 599-605

\section{Introduction}

The metabolic syndrome (MetS) is associated with multiple cardiovascular risk factors. Insulin resistance (IR) is considered as the central pathological link among these risk factors (1). Thyroid hormones have a profound effect on energy homeostasis, lipid and glucose metabolism, and blood pressure. Therefore, it is hypothesized that functional changes in the thyroid gland might have an association with MetS and its related components including obesity, IR, lipid and glucose metabolism abnormalities, and raised blood pressure (2).

Previous reports investigated functional and morphological alterations of the thyroid gland in relation to obesity (3-7). Dysregulated axis of the hypothalamus, pituitary, thyroid, and the adipose tissue was hypothesized as underlying pathophysiologic mechanisms (8, 9). Although previous studies reported inconsistant thyroid functional changes, increased TSH levels in the subjects seemed to be a consistent finding. Contradictory findings of these reports might be related to the study design, in which the investigators included patients with different severity of obesity and iodine intake (10). Additionally, in a very recent report, increased thyroid volume and nodule prevalence were also reported in patients with IR in an iodine-sufficient area for the first time (11).

Previous studies support the concept that insulin concurrently functions with TSH as a growth factor and stimulates thyroid cell proliferation. This effect 
is partially mediated via insulin-like growth factor 1 (IGF1)-dependent mechanisms; therefore, IGF1 might be involved in the pathogenesis of thyroid morphological abnormalities (11-15).

The reported clinical data about the association of MetS and its related components (IR in first line) with the thyroid gland function and morphology are extremely rare. To date, no study was performed to evaluate thyroid morphological alterations in patients with MetS in an iodine-deficient area. The objective of this study was to examine whether MetS and its related components are associated with thyroid functional and morphological changes in a mild-to-moderate iodine-deficient area.

\section{Subjects and methods}

\section{Study subjects}

The study was a single-center, prospective case-control study in patients with MetS syndrome. The Baskent University Ethics Committee for Human Studies approved the protocol. All participants provided informed consent. Two hundred and seventy-eight newly diagnosed euthyroid patients (age range, 18-74 years) with MetS who attended for regular follow-up at the Endocrinology Department of Baskent University Faculty of Medicine in Ankara, Turkey, between August 2007 and February 2009 were consecutively recruited in the study. As a control group, 261 euthyroid control subjects without known thyroid disease were recruited from patients admitting to our family practice outpatient clinic for check-up purposes. One control per case was randomly selected after subjects were stratified into <30, 30-39, 40-49, 50-59, and >60 year-old age subgroups. The controls were matched to cases according to age, gender, and smoking habits with the cases in this manner.

Euthyroidism was defined as TSH (reference range, 0.35-4.0 mIU/l), free tri-iodothyronine $\left(\mathrm{FT}_{3}\right.$; reference range, $1.71-4.71 \mathrm{pg} / \mathrm{ml})$, and free thyroxine $\left(\mathrm{FT}_{4}\right.$; reference range, $0.8-1.9 \mathrm{ng} / \mathrm{dl}$ ) within the normal reference range. The diagnostic criteria proposed by the ATP III of the National Cholesterol Education Program have been used for the definition of MetS: i) abdominal obesity, defined as a waist circumference (WC) in men $>102 \mathrm{~cm}$ and in women $>88 \mathrm{~cm}$; ii) serum triglycerides (TGs) $\geq 150 \mathrm{mg} / \mathrm{dl}$ or greater; iii) serum high-density lipoprotein (HDL) in men $<40 \mathrm{mg} / \mathrm{dl}$ and in women $<40 \mathrm{mg} / \mathrm{dl}$; iv) blood pressure $\geq 130 / 85 \mathrm{mmHg}$; and v) fasting plasma glucose $\geq 110 \mathrm{mg} / \mathrm{dl}(16)$.

The inclusion criteria were aged between 18 and 75 years. Subjects with any of the following characteristics were excluded from the study: subjects with history of thyroid disease, overt or subclinical hyperthyroidism and hypothyroidism (as defined by suppressed or elevated TSH levels respectively), previous $\mathrm{T}_{4}$ suppression therapy at any time, high thyroid autoantibody titers or history of neck irradiation or surgery were excluded. Patients were also excluded if they exhibited endocrine obesity, diabetes mellitus, pregnancy and lactation, hepatic or renal dysfunction, and history of heart failure or significant neurological or psychological illness (depression, epilepsy, schizophrenia) that will have an impact on thyroid function tests.

\section{Anthropometric measurements}

Measurements of subjects' height, weight, and WC were recorded by the same doctor. WC was measured with a folding tape at the natural waistline (the level of the umbilicus) in a horizontal plane. Body mass index (BMI) was obtained by dividing the body weight $(\mathrm{kg})$ by the square of height $(\mathrm{m})$. Each subject's fat mass (FM), percentage body fat, and free FM were recorded using a body composition analyzer (Tanita TBF-300, Tanita Corp., Tokyo, Japan).

\section{Thyroid function and morphology}

Turkey was a moderately iodine-deficient area before mandatory iodization (average urinary iodine concentration $25.5 \mu \mathrm{g} / \mathrm{l})$. Furthermore, in 1999, an obligatory model of iodine prophylaxis was initiated with iodization of household salt. The area is mildly iodine deficient (average urinary iodine concentration $92 \mu \mathrm{g} / \mathrm{l}$ ) at the moment $(17,18)$.

Thyroid ultrasonography of all subjects was performed by the same physician (S A) using a $10-\mathrm{MHz}$ linear probe (Logiq 5 Pro, GE Medical Systems, WI, USA). Volumes of thyroid glands and nodules were calculated according to the ellipsoid formula: volume $(\mathrm{ml})=$ depth $(\mathrm{cm}) \times$ width $(\mathrm{cm}) \times$ length $(\mathrm{cm}) \times \pi / 6$ (19). All patients with thyroid nodules $>1 \mathrm{~cm}$ were offered to undergo fine needle aspiration biopsy (FNAB).

\section{Laboratory analysis}

Each venous sample was drawn after a minimum fasting period of $12 \mathrm{~h}$. All samples were collected between 0800 and $0900 \mathrm{~h}$. Thyroid function was evaluated by measuring $\mathrm{FT}_{4}, \mathrm{FT}_{3}$, and $\mathrm{TSH}$ using immunochemoluminescent assays by an automated analyzer (Immulite 2000; Diagnostic Products Corp., Los Angeles, CA, USA). Thyroid antibodies (antithyroid peroxidase (normal range: $<50 \mathrm{U} / \mathrm{ml}$ ) and antithyroglobulin (normal range: $<40 \mathrm{U} / \mathrm{ml}$ )) were measured by immunochemoluminescent assays employing commercial kits (Diagnostic Products Corp). A blood sample was obtained to measure serum concentrations of fasting glucose and insulin, HDL cholesterol (HDL-C), low-density lipoprotein cholesterol (LDL-C), and TGs together with thyroid function tests and thyroid antibodies. IR was estimated based on calculation of the homeostasis model assessment (HOMA) index for 
each patient. This was done using the formula: (fasting plasma insulin $(\mathrm{IU} / \mathrm{ml}) \times$ fasting plasma glucose $(\mathrm{mmol} / \mathrm{l})) \div 22.5(20)$.

Serum glucose was measured by the glucose oxidase technique (Roche Diagnostics $\mathrm{GmbH}$ ). The serum insulin level was assayed with a solid-phase competitive chemiluminescent enzyme immunoassay (Diagnostic Product Corp). Total cholesterol, HDL-C, and TG concentrations were measured by enzymatic assay (Boehringer, Mannheim, Germany). LDL-C was calculated using Friedewald's formula: (LDL-C $=$ total cholesterol-(HDL-C + TG/5))

\section{Statistical analysis}

All continuous data were expressed as the mean \pm s.D. Data were analyzed with SPSS software (Statistical Package for the Social Sciences, version 11.0, SSPS Inc., Chicago, IL, USA). Statistical comparisons were performed by means of independent samples' $t$-tests for data with a normal distribution and $\chi^{2}$ tests for percentages. Pearson's correlation test was performed for correlation analysis. In the final multivariate analysis model, predictors of increased thyroid volume and nodule formation were selected based on both their clinical and statistical significance. A backward elimination method was applied with these results to select the most important predictor variables for thyroid volume change and the presence of thyroid nodule. Multiple linear regression analysis was used for the assessment of independent predictors of thyroid volume. Predictors of the presence of thyroid nodule were assessed by multivariate binary logistic regression analysis. Because of perfect collinearity between WC and BMI, and between IR and fasting plasma insulin levels, BMI and plasma insulin levels were excluded from the analysis. Variables that have a $P$ value of $\leq 0.20$ in univariate analysis were included into the final multivariate model. A $P$ value $<0.05$ was considered statistically significant.

\section{Results}

\section{Baseline characteristics of study population}

Study population characteristics are depicted in Table 1. As noted, the study included a total of 539 patients (278 in MetS group and 261 in control group). Among the 278 patients with MetS in the study, $92(33.1 \%)$ were male and $186(66.9 \%)$ were female. There were 261 control subjects, of whom $80(30.7 \%)$ were male and $181(69.3 \%)$ were female. Groups were matched for age, gender, and smoking habits. BMI, WC, systolic and diastolic blood pressures, and FM were significantly higher in MetS group than in control group. Fasting blood glucose (FBG), fasting insulin, HOMA-IR, LDL-C, and TG levels were also higher and HDL-C was lower in MetS group.
Table 1 Clinical, laboratory, and thyroid ultrasonography characteristics of study subjects (data are given as mean \pm s.D. as appropriate).

\begin{tabular}{lccl}
\hline & $\begin{array}{c}\text { MetS }(+) \\
(n=278)\end{array}$ & $\begin{array}{c}\text { MetS }(-) \\
(n=261)\end{array}$ & $\boldsymbol{P}$ value \\
\hline Male/female & $92 / 186$ & $80 / 181$ & $>0.05$ \\
Age (years) & $43.0 \pm 13.7$ & $42.3 \pm 13.5$ & $>0.05$ \\
Smoking (\%) & 57 & 43 & $>0.05$ \\
BMI (kg/m²) & $32.9 \pm 5.5$ & $26.5 \pm 5.1$ & $<0.0001$ \\
WC (cm) & $104.7 \pm 12.2$ & $87.2 \pm 13.0$ & $<0.0001$ \\
FFM (kg) & $54.1 \pm 11.3$ & $48.0 \pm 7.3$ & $<0.0001$ \\
FM (kg) & $34.5 \pm 10.7$ & $30.0 \pm 10.7$ & 0.016 \\
FBG (mg/dl) & $101.9 \pm 13.6$ & $91.0 \pm 10.3$ & $<0.0001$ \\
Hypertension (\%) & 55.8 & 8.8 & $<0.0001$ \\
HDL-C (mg/dl) & $40.3 \pm 10.17$ & $50.4 \pm 13.5$ & $<0.0001$ \\
LDL-C (mg/dl) & $134.5 \pm 31.3$ & $122.4 \pm 35.3$ & $<0.0001$ \\
TG (mg/dl) & $174.8 \pm 81.5$ & $101.9 \pm 51.1$ & $<0.0001$ \\
Fasting insulin (IU/ml) & $14.6 \pm 10.2$ & $7.1 \pm 6.4$ & $<0.0001$ \\
HOMA-IR & $3.7 \pm 2.8$ & $1.6 \pm 1.5$ & $<0.0001$ \\
IR (\%) & 70.4 & 8 & $<0.0001$ \\
TSH (mlU/l) & $1.6 \pm 0.9$ & $1.3 \pm 0.7$ & $<0.0001$ \\
FT $_{3}(\mathrm{pg} / \mathrm{ml})$ & $3.0 \pm 0.6$ & $2.8 \pm 0.4$ & $>0.05$ \\
$\mathrm{FT}_{4}(\mathrm{ng} / \mathrm{ml})$ & $1.1 \pm 0.2$ & $1.1 \pm 0.2$ & $>0.05$ \\
Thyroid volume (ml) & $17.5 \pm 5.5$ & $12.2 \pm 4.2$ & $<0.0001$ \\
Nodule (\%) & 50.4 & 14.6 & $<0.0001$ \\
Nodule <1 cm & $38.5 \%$ & $40.1 \%$ & $>0.05$ \\
\hline
\end{tabular}

MetS, metabolic syndrome; BMI, body mass index; WC, waist circumference; FFM, free fat mass; FM, fat mass; FBG, fasting blood glucose; HDL-C, highdensity lipoprotein cholesterol; LDL-C, low-density lipoprotein cholesterol; TG, triglyceride; HOMA-IR, homeostasis model assessment of insulin resistance; $F T_{3}$, free $T_{3} ; \mathrm{FT}_{4}$, free $\mathrm{T}_{4}$.

\section{Thyroid function and morphology}

Serum concentrations of $\mathrm{FT}_{3}$ and $\mathrm{FT}_{4}$ were not significantly different between MetS and control groups (Table 1). Mean TSH level in MetS group was higher than control group $(1.56 \pm 0.85$ vs $1.33 \pm 0.73 \mathrm{mIU} / \mathrm{l}$, $P<0.0001)$. As shown in Table 1 , mean thyroid volume was significantly higher in MetS patients than in controls $(17.5 \pm 5.5$ vs $12.2 \pm 4.2 \mathrm{ml}, P<0.0001)$. Percentage of patients with thyroid nodules was also significantly higher in MetS patients than in controls ( 50.4 vs $14.6 \%, P<0.0001$ ). The size of the nodule was $<1 \mathrm{~cm}$ in $38.5 \%$ of patients with MetS and $40.1 \%$ of control subjects $(P>0.05)$. In comparison of MetS and control groups, subjects were stratified into $<30$, $30-39,40-49,50-59$, and $>60$ year-old age subgroups; in all age subgroups, thyroid volumes and percentage of patients with thyroid nodules were significantly higher in patients with MetS than in controls. All study subjects were also divided into two groups with respect to the presence of IR. As depicted in Table 2, subjects with IR $(n=213)$ had increased thyroid volumes $(17.6 \pm 5.5$ vs $13.3 \pm 5.0 \mathrm{ml}$, $P<0.0001)$ and nodule formation $(48.3$ vs $22.6 \%$, $P<0.0001)$ compared with subjects without IR $(n=326)$. The odds ratio (OR) for the development of thyroid nodule in the presence of IR was $3.2(95 \%$ confidence interval). 
Table 2 Thyroid morphological changes in respect to insulin resistance (IR; data are given as mean \pm s.D. as appropriate).

\begin{tabular}{|c|c|c|c|c|c|c|}
\hline \multirow[b]{2}{*}{ Age groups $(n)$} & \multicolumn{2}{|c|}{ Thyroid nodule } & \multirow{2}{*}{$\begin{array}{l}\boldsymbol{P} \text { value } \\
\text { (nodule) }\end{array}$} & \multicolumn{2}{|c|}{ Thyroid volume (ml) } & \multirow[b]{2}{*}{$\boldsymbol{P}$ value (volume) } \\
\hline & Present (\%) IR (+) & Absent (\%) IR (-) & & $\operatorname{IR}(+)$ & $\operatorname{IR}(-)$ & \\
\hline$<30(n=101)$ & 38.5 & 10.30 & 0.001 & $17.9 \pm 4.8$ & $13.3 \pm 3.6$ & $<0.0001$ \\
\hline $30-39(n=149)$ & 37.3 & 13.60 & 0.001 & $17.9 \pm 5.5$ & $13.9 \pm 4.5$ & $<0.0001$ \\
\hline $40-49(n=92)$ & 50.0 & 23.1 & 0.008 & $18.1 \pm 5.2$ & $13.8 \pm 5.9$ & 0.001 \\
\hline $50-59(n=119)$ & 59.6 & 37.5 & 0.015 & $18.1 \pm 5.9$ & $13.5 \pm 5.5$ & $<0.0001$ \\
\hline$>60(n=78)$ & 65.4 & 30.6 & 0.004 & $14.9 \pm 6.1$ & $11.3 \pm 5.3$ & 0.017 \\
\hline Total $(n=539)$ & 48.3 & 22.6 & $<0.0001$ & $17.6 \pm 5.5$ & $13.3 \pm 5.0$ & $<0.0001$ \\
\hline
\end{tabular}

As shown in Table 3, in univariate analysis, serum TSH was positively and significantly correlated with BMI $\quad(r=0.176, \quad P<0.0001), \quad$ WC $\quad(r=0.118$, $P=0.007)$, and FM $(r=0.164, P=0.042)$. There was no correlation between HOMA-IR and TSH. Thyroid volume was significantly higher in smokers compared with nonsmokers $(15.9 \pm 5.4$ vs $14.6 \pm 5.6, P=0.02)$. Thyroid volume was significantly correlated with TSH $(r=0.146, P=0.001)$ and with related components of MetS (BMI $(r=0.355, P<0.0001)$, WC $(r=0.458$, $P<0.0001)$, hypertension $(P<0.0001), \quad$ FBG $(r=0.146, P=0.001)$, HDL $(r=-0.214, P<0.0001)$, serum TG $(r=0.018, P<0.0001)$, and HOMA-IR $(r=0.215, P<0.0001))$. Multiple linear regression analysis was used for the assessment of independent predictors of thyroid volume (Table 4). Variables that have a $P$ value of $\leq 0.20$ in univariate analysis were included in the final multivariate model. Among the variables mentioned above, WC, IR, serum TGs, and smoking remained independently correlated with thyroid volume $(\beta=0.335, P<0.0001 ; \beta=0.143$, $P=0.004 ; \beta=0.136, P=0.003 ; \beta=0.092, P=0.029$ respectively). Predictors of the thyroid nodule formation were assessed by multivariate binary logistic regression analysis (Table 5). In the multivariate model, IR, hypertension, and FBG $(\beta=0.62, P=0.005 ; \beta=1.04$, $P<0.001 ; \beta=0.02, P=0.035$ respectively) remained independently correlated with thyroid nodule formation, providing evidence that IR is an independent risk factor for nodule formation.

All patients with thyroid nodules $>1 \mathrm{~cm}$ were offered to undergo FNAB. Three thyroid cancer cases were diagnosed in 38 MetS patients $(7.9 \%)$ with thyroid nodules undergoing FNAB, while none of the biopsied control subjects $(n=22)$ with thyroid nodules had thyroid cancer.

\section{Discussion}

MetS is a cluster of risk factors including increased blood pressure, abdominal obesity, lipid abnormalities, and impaired glucose metabolism. Individuals with MetS have much higher risk for cardiovascular diseases (1). Thyroid hormones appear to serve as a general metabolic controller coordinating many metabolic processes and, as shown in previous studies, they may be associated with MetS and/or its related components $(11,21-23)$. Recently, an intriguing area of research in thyroidology is the association of MetS (or its related components) with thyroid functional/morphological abnormalities (11). In almost all of these studies, consistent relationship between obesity and thyroid functional changes was reported, thus supporting the

Table 3 The relation between components of metabolic syndrome and thyroid morphological changes along with TSH.

\begin{tabular}{|c|c|c|c|c|c|}
\hline & \multicolumn{2}{|c|}{ TSH } & \multicolumn{2}{|c|}{ Thyroid volume } & \multirow{2}{*}{$\begin{array}{c}\text { Thyroid nodule } \\
P \text { value }\end{array}$} \\
\hline & $P$ value & $r$ & $P$ value & $r$ & \\
\hline WC (cm) & 0.007 & 0.118 & $<0.0001$ & 0.458 & $<0.0001$ \\
\hline FBG (mg/dl) & 0.834 & 0.009 & 0.001 & 0.146 & $<0.0001$ \\
\hline HDL (mg/dl) & 0.533 & -0.29 & $<0.0001$ & -0.214 & 0.160 \\
\hline LDL (mg/dl) & 0.282 & -0.049 & 0.707 & -0.018 & 0.022 \\
\hline TG (mg/dl) & 0.415 & 0.036 & $<0.0001$ & 0.304 & 0.003 \\
\hline Hypertension & 0.681 & & $<0.0001$ & & $<0.0001$ \\
\hline Fasting insulin & 0.929 & 0.004 & $<0.0001$ & 0.246 & $<0.0001$ \\
\hline HOMA-IR & 0.870 & -0.008 & $<0.0001$ & 0.215 & 0.007 \\
\hline IR & 0.103 & & $<0.0001$ & & $<0.0001$ \\
\hline BMI $\left(\mathrm{kg} / \mathrm{m}^{2}\right)$ & $<0.0001$ & 0.176 & $<0.0001$ & 0.355 & $<0.0001$ \\
\hline FM (kg) & 0.042 & 0.161 & 0.444 & 0.064 & 0.220 \\
\hline FFM (kg) & 0.053 & 0.157 & 0.002 & 0.256 & 0.960 \\
\hline
\end{tabular}

WC, waist circumference; FBG, fasting blood glucose; HDL-C, high-density lipoprotein cholesterol; LDL, low-density lipoprotein cholesterol; TG, triglyceride; HOMA-IR, homeostasis model assessment of insulin resistance; BMI, body mass index; FM, fat mass; FFM, free fat mass. 
Table 4 Multiple linear regression analysis for the assessment of independent predictors of thyroid volume.

\begin{tabular}{lcccrr}
\hline & \multicolumn{3}{c}{ Thyroid volume } \\
\cline { 2 - 6 } & $\beta$ & S.E.M. & $t$ & \multicolumn{1}{c}{$P$ value } & $95 \%$ Cl \\
\hline WC & 0.335 & 0.018 & 6.881 & $<0.0001$ & $0.089-0.161$ \\
TG & 0.136 & 0.003 & 2.982 & $0.003-0.016$ \\
IR & 0.143 & 0.564 & 2.872 & 0.004 & $0.512-2.731$ \\
Smoking & 0.092 & 0.538 & 2.189 & 0.029 & $0.120-2.234$ \\
\hline
\end{tabular}

WC, waist circumference; TG, triglyceride; IR, insulin resistance; $\mathrm{Cl}$, confidence interval for $\beta$.

hypothesis that the axis involving the hypothalamus, the pituitary, the thyroid, and the adipose tissue was somehow disrupted $(8,9)$. Although previous studies evaluating thyroid functional changes in obese patients reported discrepant findings, the most consistently reported finding is that the serum levels of TSH are higher in obese patients than in healthy controls (3-7). Unlike TSH, data regarding the circulating levels of free thyroid hormones are discrepant between different studies, which reported either increased or decreased serum concentrations of $\mathrm{FT}_{3}$ or $\mathrm{FT}_{4}$ (3-5). Previous studies have shown that low normal free thyroid hormone levels and/or elevated TSH levels were significantly associated with MetS and its components (5-7, 24-26). In our study, we could not find an association between serum-free thyroid hormones $\left(\mathrm{FT}_{4}\right.$ and $\mathrm{FT}_{3}$ ) and the presence of MetS diagnosis. But we found that serum TSH level was higher in patients with MetS than in controls, and TSH level was significantly positively correlated with BMI and WC. There have been some studies suggesting that some humoral or hormonal mediators from adipose tissue stimulate the hypothalamus-pituitary-thyroid axis in order to increase TSH secretion $(3,27)$. The main suspected mechanism is a possible relationship between leptin and the thyroid hormones. There is possibly a relationship between leptin and the thyroid hormones via an influence of leptin on the negative feedback regulation of thyroid hormones. Leptin regulates TRH expression (28). Recent evidence has suggested that the relationship between leptin levels and FM is curvilinear, so that leptin secretion increases exponentially with increasing FM (29). Insulin also increases total leptin levels (30). Thus, increased FM along with IR in MetS patients may contribute to increased serum TSH levels via effects on serum leptin concentrations (31). The relationship between increased TSH levels with BMI can also be expressed in the reverse manner. Animal and human studies have yielded convincing evidence that adipocytes and preadipocytes express TSH receptors (32). The action of TSH on its receptors in fat tissue induces differentiation of preadipocytes into adipocytes, causing stimulation of adipogenesis (33). All of these reciprocal mechanisms suggest that leptin and the thyroid axis maintain a complex and dual relationship and it might be proposed that a 'hypothalamic-pituitarythyroid-adipose axis' exists.
In a previous report by Rezzonico et al., patients with IR have larger thyroid volumes and higher risk for formation of thyroid nodules (11). Our study yielded a comparable result with a previous report by Rezzonico et al. indicating that subjects with IR have a larger thyroid gland volume by ultrasound and have a significantly increased thyroid nodule prevalence. The corresponding OR for the development of thyroid nodule formation in our study was 3.1.

TSH is a major hormone that plays an important role in regulating the growth and differentiation of thyroid cells (34). Our study further confirmed that increased serum TSH is an independent risk factor for thyroid volume increase in patients with MetS. Besides TSH, all related components of MetS were significantly associated with increased thyroid volume. However, in our study, we could not find an association between TSH and thyroid nodule formation. Our study suggests that increased thyroid volume in patients with MetS is related to TSH. However, TSH-independent mechanisms might be involved in thyroid nodule formation in patients with MetS.

IGF1 is actively involved in the TSH-mediated proliferation of thyrocytes. Insulin/IGF1-signaling pathway has long been known to modulate the regulation of thyroid gene expression and might be considered as additional important factors in thyrocyte proliferation and differentiation $(35,36)$. TSH is a wellknown mitogen in the presence of insulin in cell cultures, and it also suppresses apoptotic cell death in response to various stimuli (37). Although causal relationship was not specifically raised, numerous studies put an association between thyroid volume and BMI. In most of these studies, thyroid volume is significantly positively correlated with BMI $(38,39)$.

Table 5 Multivariate binary logistic regression analysis for the assessment of independent predictors of thyroid nodule formation.

\begin{tabular}{lcrrr}
\hline & \multicolumn{4}{c}{ Thyroid nodule } \\
\cline { 2 - 5 } & $\beta$ & S.E.M. & $P$ value & OR $(95 \%$ CI) \\
\hline Hypertension & 1.035 & 0.217 & $<0.001$ & $2.81(1.84-4.31)$ \\
FBG & 0.018 & 0.009 & 0.035 & $1.02(1.00-1.04)$ \\
IR & 0.623 & 0.222 & 0.005 & $1.87(1.21-2.88)$ \\
\hline
\end{tabular}

$\mathrm{OR}$, odds ratio; $\mathrm{Cl}$, confidence interval for $\beta$; $\mathrm{FBG}$, fasting blood glucose; $\mathrm{IR}$, insulin resistance. 
Our data suggest that among typical metabolic abnormalities of MetS, IR- and MetS-related components may contribute to increased thyroid volume and nodule prevalence. In multivariate analysis, among the variables that will have an effect on nodule formation, IR, but not TSH, was associated with increased nodule formation. These data are in agreement with results of Rezzonico et al. that highlighted the insulin level as predictor of thyroid volume increase.

MetS has been associated with high risks of several common adult cancers. Although exact molecular mechanisms and the pathophysiology responsible for increased risk are not fully understood, the most likely mechanism seems to be IR (40). Although the mortality rate has remained stable, the incidence of thyroid cancer is rising (41). Similarly, in the USA, the prevalence of obesity has increased from $15.3 \%$ in 1995 to $23.9 \%$ in 2005 (42). Although this recent rise in thyroid cancer is likely related to improved imaging modalities, altered histopathologic criteria for diagnosis of thyroid cancer, and nuclear exposure, it should be questioned whether there are other modifiable risk factors contributing to this increased risk $(41,43)$. In a very recent analysis, a significant association of IR with differentiated thyroid cancer was reported by Rezzonico et al. They concluded that a high prevalence of IR would be an important risk factor for developing differentiated thyroid cancer, as it is well known with some other nonthyroid carcinomas (44). Three malignant thyroid nodules by FNAB were found in 3 out of $29(7.1 \%)$ thyroid nodules. None of the biopsied patients in the control group were found to have thyroid cancer. In our unpublished unselected case series within the same period of present study, malignancy detection rate was $2.7 \%$ in patients with nodular thyroid disease who underwent FNAB. Although our sample size might not have been sufficient to detect a small difference in observed malignancy between groups if one existed, this issue warrants further studies with larger sample size in order to reach a definite conclusion whether thyroid cancer rate is increased in patients with MetS or not.

\section{Conclusion}

Our study is a case-control study performed in subjects admitted to hospital, but, to our knowledge, this is the largest prospective study that has investigated the association of MetS and its components with morphological abnormalities of the thyroid gland. MetS patients had similar serum $\mathrm{FT}_{4}$ concentrations with control subjects. On the other hand, patients with MetS showed significantly higher serum concentrations of TSH when compared with healthy controls. Both thyroid volume and nodule prevalence were increased in MetS patients. Our study also showed that subjects with IR exhibited a higher significant relative risk for thyroid nodule formations and thyroid volume increase. Our data further emphasize the possible pivotal role of insulin/ IGF1 axis in thyroid volume and nodule formation.

\section{Declaration of interest}

There is no conflict of interest that could be perceived as prejudicing the impartiality of the research reported.

\section{Funding}

This research did not receive any specific grant from any funding agency in the public, commercial, or not-for-profit sector.

\section{References}

1 Reaven GM. Banting lecture 1988. Role of insulin resistance in human disease. Diabetes 198837 1595-1607.

2 Kokkoris $\mathrm{P} \& \mathrm{Pi}$-Sunyer FX. Obesity and endocrine disease. Endocrinology and Metabolism Clinics of North America 200332 895-914.

3 Sari R, Balci MK, Altunbas H \& Karayalcin U. The effect of body weight and weight loss on thyroid volume and function in obese women. Clinical Endocrinology $200359258-262$.

4 Michalaki MA, Vagenakis AG, Leonardou AS, Argentou MN, Habeos IG, Makri MG, Psyrogiannis AI, Kalfarentzos FE \& Kyriazopoulou VE. Thyroid function in humans with morbid obesity. Thyroid 200616 73-78.

5 De Pergola G, Ciampolillo A, Paolotti S, Trerotoli P \& Giorgino R. Free triiodothyronine and thyroid stimulating hormone are directly associated with waist circumference, independently of insulin resistance, metabolic parameters and blood pressure in overweight and obese women. Clinical Endocrinology 200767 265-269.

6 Bastemir M, Akin F, Alkis E \& Kaptanoglu B. Obesity is associated with increased serum TSH level, independent of thyroid function. Swiss Medical Weekly 2007137 431-434.

7 Knudsen N, Laurberg P, Rasmussen LB, Bülow I, Perrild H, Ovesen L \& Jørgensen T. Small differences in thyroid function may be important for body mass index and the occurrence of obesity in the population. Journal of Clinical Endocrinology and Metabolism $2005904019-4024$.

8 Schäffler A, Binart N, Schölmerich J \& Büchler C. Hypothesis paper Brain talks with fat - evidence for a hypothalamic-pituitaryadipose axis? Neuropeptides 200539 363-367.

9 Pontikides N \& Krassas GE. Basic endocrine products of adipose tissue in states of thyroid dysfunction. Thyroid 200717 421-431.

10 Rotondi M, Leporati P, La Manna A, Pirali B, Mondello T, Fonte R, Magri F \& Chiovato L. Raised serum TSH levels in patients with morbid obesity: is it enough to diagnose subclinical hypothyroidism? European Journal of Endocrinology $2009160403-408$.

11 Rezzonico J, Rezzonico M, Pusiol E, Pitoia F \& Niepomniszcze H. Introducing the thyroid gland as another victim of the insulin resistance syndrome. Thyroid $2008 \mathbf{1 8} 461-464$.

12 Van Keymeulen A, Dumont JE \& Roger PP. TSH induces insulin receptors that mediate insulin costimulation of growth in normal human thyroid cells. Biochemical and Biophysical Research Communications 2000279 202-207.

13 Kimura T, Van Keymeulen A, Golstein J, Fusco A, Dumont JE \& Roger PP. Regulation of thyroid cell proliferation by TSH and other factors: a critical evaluation of in vitro models. Endocrine Reviews 200122 631-656.

14 Deleu S, Pirson I, Coulonval K, Drouin A, Taton M, Clermont F, Roger PP, Nakamura T, Dumont JE \& Maenhaut C. IGF-1 or insulin, and the TSH cyclic AMP cascade separately control dog 
and human thyroid cell growth and DNA synthesis, and complement each other in inducing mitogenesis. Molecular and Cellular Endocrinology 1999149 41-51.

15 Kimura T, Dumont JE, Fusco A \& Golstein J. Insulin and TSH promote growth in size of $\mathrm{PC} \mathrm{Cl3}$ rat thyroid cells, possibly via a pathway different from DNA synthesis: comparison with FRTL-5 cells. European Journal of Endocrinology 1999140 94-103.

16 Expert Panel on Detection, Evaluation, and Treatment of High Blood Cholesterol in Adults. Executive Summary of the Third Report of the National Cholesterol Education Program (NCEP) Expert Panel on Detection, Evaluation, and Treatment of High Blood Cholesterol in Adults (Adult Treatment Panel III). Journal of the American Medical Association 2001285 2486-2497.

17 Erdoğan G, Erdogan MF, Emral R, Baştemir M, Sav H, Haznedaroğlu D, Ustündağ M, Köse R, Kamel N \& Genç Y. Iodine status and goiter prevalence in Turkey before mandatory iodization. Journal of Endocrinological Investigation $2002 \mathbf{2 5}$ $224-228$

18 Erdoğan MF, Demir O, Emral R, Kamel AN \& Erdoğan G. More than a decade of iodine prophylaxis is needed to eradicate goiter among school age children in a moderately iodine-deficient region. Thyroid $200919265-268$.

19 Brunn J, Block U, Ruf G, Bos I, Kunze WP \& Scriba PC. Volumetric analysis of thyroid lobes by real-time ultrasound. Deutsche Medizinische Wochenschrift 1981106 1338-1340.

20 Matthews DR, Hosker JP, Rudenski AS, Naylor BA, Treacher DF \& Turner RC. Homeostasis model assessment: insulin resistance and beta-cell function from fasting plasma glucose and insulin concentrations in man. Diabetologia 198528 412-419.

21 Park HT, Cho GJ, Ahn KH, Shin JH, Hong SC, Kim T, Hur JY, Kim YT, Lee KW \& Kim SH. Thyroid stimulating hormone is associated with metabolic syndrome in euthyroid postmenopausal women. Maturitas 200962 301-305.

22 De Pergola G, Giorgino F, Benigno R, Guida P \& Giorgino R. Independent influence of insulin, catecholamines, and thyroid hormones on metabolic syndrome. Obesity 200816 2405-2411.

23 Roos A, Bakker SJ, Links TP, Gans RO \& Wolffenbuttel BH. Thyroid function is associated with components of the metabolic syndrome in euthyroid subjects. Journal of Clinical Endocrinology and Metabolism 200792 491-496.

24 Bruckert E, Giral P, Chadarevian R \& Turpin G. Low free-thyroxine levels are a risk factor for subclinical atherosclerosis in euthyroid hyperlipidemic patients. Journal of Cardiovascular Risk 19996 327-331.

25 Lin SY, Wang YY, Liu PH, Lai WA \& Sheu WH. Lower serum free thyroxine levels are associated with metabolic syndrome in a Chinese population. Metabolism $2005 \mathbf{5 4} 1524-1528$.

26 Kim BJ, Kim TY, Koh JM, Kim HK, Park JY, Lee KU, Shong YK \& Kim WB. Relationship between serum free $\mathrm{T}_{4}\left(\mathrm{FT}_{4}\right)$ levels and metabolic syndrome (MS) and its components in healthy euthyroid subjects. Clinical Endocrinology 200970 152-160.

27 Rosenbaum M, Hirsch J, Murphy E \& Leibel RL. Effects of changes in body weight on carbohydrate metabolism, catecholamine excretion, and thyroid function. American Journal of Clinical Nutrition 200071 1421-1432.

28 Zimmermann-Belsing T, Brabant G, Holst JJ \& Feldt-Rasmussen U. Circulating leptin and thyroid dysfunction. European Journal of Endocrinology 2003149 257-271.
29 Mantzoros CS \& Moschos SJ. Leptin: in search of role(s) in human physiology and pathophysiology. Clinical Endocrinology $1998 \mathbf{4 9}$ 551-567.

30 Lewandowski K, Randeva HS, O'Callaghan CJ, Horn R, Medley GF, Hillhouse EW, Brabant G \& O'Hare P. Effects of insulin and glucocorticoids on the leptin system are mediated through free leptin. Clinical Endocrinology 200154 533-539.

31 Menendez C, Baldelli R, Camiña JP, Escudero B, Peino R, Dieguez C \& Casanueva FF. TSH stimulates leptin secretion by a direct effect on adipocytes. Journal of Endocrinology 2003176 7-12.

32 Sorisky A, Bell A \& Gagnon A. TSH receptor in adipose cells. Hormone and Metabolic Research 200032 468-474.

33 Valyasevi RW, Harteneck DA, Dutton CM \& Bahn RS. Stimulation of adipogenesis, peroxisome proliferator-activated receptorgamma (PPARgamma), and thyrotropin receptor by PPARgamma agonist in human orbital preadipocyte fibroblasts. Journal of Clinical Endocrinology and Metabolism 200287 2352-2358.

34 Rapoport B, Chazenbalk GD, Jaume JC \& McLachlan SM. The thyrotropin (TSH) receptor: interaction with TSH and autoantibodies. Endocrine Reviews 199819 673-716.

35 Mohan S, Baylink DJ \& Pettis JL. Insulin-like growth factor (IGF)binding proteins in serum - do they have additional roles besides modulating the endocrine IGF actions? Journal of Clinical Endocrinology and Metabolism 199681 3817-3820.

36 Santisteban P, Acebrón A, Polycarpou-Schwarz M \& Di Lauro R. Insulin and insulin-like growth factor I regulate a thyroid-specific nuclear protein that binds to the thyroglobulin promoter. Molecular Endocrinology 19926 1310-1317.

37 Li X, Lu S, Miyagi E, Katoh R \& Kawaoi A. Thyrotropin prevents apoptosis by promoting cell adhesion and cell cycle progression in FRTL-5 cells. Endocrinology 1999140 5962-5970.

38 Hegedüs L, Perrild H, Poulsen LR, Andersen JR, Holm B, Schnohr P, Jensen G \& Hansen JM. The determination of thyroid volume by ultrasound and its relationship to body weight, age, and sex in normal subjects. Journal of Clinical Endocrinology and Metabolism 198356 260-263.

39 Semiz S, Senol U, Bircan O, Gümüşlü S, Bilmen S \& Bircan I. Correlation between age, body size and thyroid volume in an endemic area. Journal of Endocrinological Investigation $2001 \mathbf{2 4}$ 559-563.

40 Pothiwala P, Jain SK \& Yaturu S. Metabolic syndrome and cancer. Metabolic Syndrome and Related Disorders 20097 279-288.

41 Richardson DB. Exposure to ionizing radiation in adulthood and thyroid cancer incidence. Epidemiology 200920 181-187.

42 Bessesen DH. Update on obesity. Journal of Clinical Endocrinology and Metabolism 200893 2027-2034.

43 Grodski S, Brown T, Sidhu S, Gill A, Robinson B, Learoyd D, Sywak M, Reeve T \& Delbridge L. Increasing incidence of thyroid cancer is due to increased pathologic detection. Surgery 2008144 1038-1043.

44 Rezzónico JN, Rezzónico M, Pusiol E, Pitoia F \& Niepomniszcze H. Increased prevalence of insulin resistance in patients with differentiated thyroid carcinoma. Metabolic Syndrome and Related Disorders 20097 375-380.

Received 15 July 2009

Accepted 21 July 2009 